\title{
Enhancing Rehabilitation Counselor Skill Development through Experiential Learning in a Distance Education Environment
}

\author{
Raymond C. Ortega,William E. Garner* \\ University of Arkansas at Little Rock, Little Rock, AR 72211, United States \\ *Corresponding Author: wegarner@ualr.edu
}

\begin{abstract}
Research has indicated that beginning Rehabilitation Counselors frequently lack understanding about the process of identifying and developing collaborative relationships with community agencies. Even if they recognize the need, it is often outside of their comfort zone. One reason that counseling students and professionals may be hesitant to engage in this activity is related to a lack of exposure to the process. Incorporation of experiential learning assignments throughout the rehabilitation counseling program is a potent approach to address this issue. The types of experiential learning tasks and projects, incorporated into a large, online Master's Degree program in Rehabilitation Counseling, are discussed. This learning model has applications to many different types of human services education programs that are delivered primarily online.
\end{abstract}

Keywords Experiential Learning, Service Learning Tasks, Distance Learning, Rehabilitation Counseling Education

\section{Introduction}

The field of rehabilitation counseling is a specialty within the rehabilitation profession with counseling at its core, and is differentiated from other related counseling fields. In addition to possessing sound counseling skills, Rehabilitation Counselors must also be knowledgeable in the effects of disabilities on employment, independence in daily activities, and the individual's roles within family and community systems (Maki \&Tarvydas, 2011).

The rehabilitation process typically includes: case management, referral, and service coordination; interventions to remove environmental, employment, and attitudinal barriers; consultation services among multiple parties and regulatory systems; job analysis, job development, and placement services, including assistance with employment and job accommodations; and the provision of consultation about and access to rehabilitation technology. In all of these activities, the Rehabilitation Counselor must interact with other healthcare professionals, community resources and third party vendors to secure the appropriate services (Rubin \& Roessler, 2008).

According to information available from the Commission on Rehabilitation Counselor Certification (CRCC), Rehabilitation counselors work across many employment settings, both in the public and private sectors, including: Business \& Industry, Mental Health Centers/Psychiatric Facilities, Developmental Disabilities Facilities, Native American \& Alaskan Community Programs, Colleges \& Universities, Rehabilitation Hospitals, Community Rehabilitation Programs, Private Rehabilitation Companies, Corrections Facilities, Private Practice/Self-Employed, Independent Living Facilities, State Rehabilitation Agencies, Insurance Companies, Veterans Benefits Administration, K-12 Schools, Veterans Health Administration Medical Centers, and Workers' Compensation Agencies.

The approximate distribution of counselors in various job settings is:

Private, for profit $-43 \%$

State-federal - $18 \%$

Private non-profit $-14 \%$

Mental health $-7 \%$

Medical/hospitals - 5\%

College/university $-4 \%$

Public schools $-2 \%$

Other $-8 \%$

The largest area of job growth in recent years has occurred in the private sector due to increased emphasis on cost containment and health care reform (Chan, Leahy, Lui, \& Shaw, 1997). One of the implications listed in that study was rehabilitation counselors perceived a strong need to be knowledgeable about community-based services and the resources required for community reentry. At the same time, the participants indicated that they did not feel well prepared in these areas.

Seven major job functions have been identified as central to the professional practice of rehabilitation counseling: (a) 
vocational counseling and consultation, (b) counseling interventions, (c) community-based rehabilitation service activities, (d) case management, (e) applied research, (f) assessment, and (g) professional advocacy (Chan, Chronister, Allen, Catalano, \& Lee, 2004). A primary task within the community-based rehabilitation service function was researching resources and funding available in the community. That study further identified knowledge of rehabilitation services and resources as well as healthcare and disability systems as important areas for rehabilitation practice.

Several studies were cited in an article regarding counseling students' advocacy competencies (Murray, Pope, \& Rowell, 2010) which suggested that low levels of participation in these activities could be related to a lack of training. The article further suggests that one possible avenue for improving training in this area might be the incorporation of opportunities to develop and practice these skills through experiential learning activities. The project discussed in this article resulted in some positive student gains. Students reported that the project helped to broaden their perspective of the issue, increase their understanding of public policy decision-making, and develop a higher level of competence and self-efficacy in performing these tasks.

Similar gains were suggested in an article regarding pre-practicum service learning in counselor education (Jett \& Delgado-Romero, 2009). They suggested that this mode of learning can contribute to increased multicultural competence, provide a "first glimpse" of counseling-related activities and provide a bridge between counseling theory and practice. The report from the 35 th Institute on Rehabilitation Issues ("eLearning and Vocational Rehabilitation," 2010) suggested that the online delivery of rehabilitation counseling education enabled students and faculty to work in a shared forum to ask questions and develop solutions to problems encountered in work settings. They saw the development of communities of practice, real world applications and professional experience as being more easily achieved in the distance learning environment than in the traditional classroom.

\section{Experiential Learning}

"Experiential Learning is an approach to learning in which participants engage in an activity, reflect on the activity critically, and obtain useful insight and learning; a "hands on", "learning by doing" approach. Learning which is developed experientially is "owned" by the learner and becomes an effective and integral aspect of behavioral change." (Experiential Learning,n.d.). So, to operationalize this definition, experiential learning can involve a wide variety of activities, but have some common characteristics. First of all, the activities can, and most often do, occur outside of the classroom. Second, the objectives of the activity are planned and articulated prior to the experience. Third, there is an opportunity for analysis and reflection regarding the experience.

Within the higher education setting, experiential learning can take on many forms ranging from participation in simulated scenarios to field experience, service learning and practicum and internship experiences.

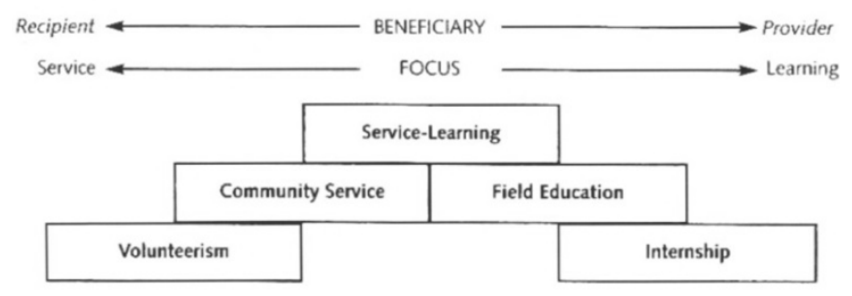

Figure 1. The Experiential Learning Continua and Levels

As the illustration in Figure 1 shows, the various levels of experiential learning move along two continua. The first (Beneficiary) addresses whether the recipient or the provider derives the most benefit from the experience. The second (Focus) indicates whether the primary activity is service or learning. For example, in community service, the recipient of the service is the primary beneficiary and the focus is mostly on delivery of the service. On the other hand, an internship would primarily benefit the provider (student) and would focus primarily on the learning experience rather than the actual service (Furco, 1996).

Service Learning falls between these two with a balanced position on both continua. While there is a very real service being provided, the activity is rooted in the academic course content. As a result, the student benefits in getting a better understanding of the course content, and the recipient benefits from a real service being provided. As the illustration indicates, there is some degree of overlap among the categories.

\section{The Program}

The primary program, under discussion, is a 54 semester-hour Master of Arts Degree in Rehabilitation Counseling (MRC). In addition, the additional coursework is offered that is typically needed to meet State licensure requirements as a Licensed Professional Counselor. From its inception, the MRC program has been offered as an entirely online program. The program is fully accredited by the Council on Rehabilitation Education (CORE). Currently, the program serves 146 active students from all sections of the country as well as several foreign countries and active military deployed around the world. As a program requirement, all students participate in two skill development workshops in conjunction with the individual and group counseling classes. They also complete 15 semester hours of fieldwork (Practicum and Internship) in the latter stages of the program.

Conducting a graduate program entirely online does impose some different challenges. The classes are conducted, asynchronously, using Blackboard 9.1 as the learning 
platform. Within this structure, instructors can make use of learning modules, e-mail, discussion forums, assignments, and assessments. The typical weekly class session incorporates lectures via video streams, homework assignments, quizzes/exams, interactive discussions and handouts. In the Practicum and Internship experiences, collaboration and communication between the students and the instructors takes place via email, phone, discussion boards, or video conferencing. Although interaction with the students using these modalities works well in most cases, feedback from students, fieldwork supervisors, and employers prompted the program to seek better ways to prepare the students for interaction with clients, other service providers, and community resources prior to initiating their Practicum and Internship experiences.

\section{What was Lacking}

The program found that students entering their fieldwork near the end of the MRC program often lacked confidence in their ability to:

1) Analyze client needs

2) Identify available resources

3) Make effective referrals to community resources (applications, eligibility criteria, funding)

4) Understand how external resources actually work

5) Monitor service delivery, and

6) Assess service value.

In addition, students expressed anxiety over making "cold calls", had minimal understanding of becoming part of a treatment team, and did not recognize the legal and ethical issues involved with shared cases.

\section{The Solution}

In response to these areas of concern, experiential learning tasks were incorporated into several classes, throughout the program, prior to students getting into the Practicum or Internship phase of program. They were designed to be consistent with the overall learning goals for those particular classes as well as to provide incremental exposure to the "outside world". The incremental progression of the experiential learning allowed students to begin with activities that were not tremendously stressful, yet provided an opportunity to see how the concepts and skills discussed in the classes translated into actual practice.

Certainly, this solution is not unique to this particular program. A review of the program websites for many institutions speak about the importance of early fieldwork experiences in fields such as Teaching, Social Work, and Counseling. The posting by the Teacher Development Center at the University of Texas at Dallas (“Early_Field_Experience,"n.d.) summarizes it well: "Early field experience is a valuable learning opportunity, but it is most effective when closely related to the content of the course with which it is associated. Students need to have guidance about what they are observing and why."

Within the field of Counseling and more specifically Rehabilitation Counseling the need for actual contact with clients, community resource providers, and other professionals throughout the training program is clearly specified in the accreditation standards of the Council for the Accreditation of Counseling and Related Educational Programs [CACREP] (2009) and the Council on Rehabilitation Education[CORE] (2010). The latter standard states: "The program shall provide evidence of opportunities throughout the course of study for interactive and collaborative experiences with individuals with disabilities in a variety of roles and settings."

In the progression through the MRC program, the initial project during the Foundations of Rehabilitation class is largely observational. The level of participation is increased to taking an active role in seeking and taking a vocational instrument in the Assessment in Rehabilitation class, andin conducting a job analysis in the Career Counseling and Placement class. Participation is further increased in the extended participation incorporated into the Service Learning Task in the Rehabilitation Case Management (RCM) class. Finally, the student is exposed to extended client encounters over multiple counseling sessions. In the Internship, the student participates in the full range of activities associated with working as a Rehabilitation or Mental Health Counselor. An integral part of all of these activities is the completion of at least one reflection paper documenting the experience as well as the students' feelings about what they learned from it.

The first class taken by new students is Foundations of Rehabilitation. In this class, students are required to engage in a Site Visit/Shadowing Experience during which they spend $1 / 2$ day with an experienced Rehabilitation Counselor. The instructions for this assignment require them to identify an appropriate rehabilitation professional and to set up their own appointment. Once the meeting is completed, the student is required to complete a report of what they found out about the duties and work setting as well as their feelings about the experience. They are not provided with any suggested resources or specific contacts. This is done to address the earlier concerns regarding the identification of appropriate resources and making the "cold calls" to schedule the meeting.

The next course into which experiential learning has been incorporated is Assessment in Rehabilitation. The assignment here is to locate a site to visit where an experienced professional can give them an assessment instrument and interpret the results for them. Again, the student is responsible for locating an appropriate site and to arrange for the visit. The goal is for the student to observe the way the professional sets up the test session with attention to physical arrangements, observance of test instructions and administration, scoring and interpretation, and discussion of 
the results with the client. The anticipated outcome is for the student to observe what happens in a testing situation and to acquire a sense of how their future clients might feel about the test administration process.

In the Career Counseling and Placement class, students must locate a site to visit and do a Job Analys is on a professional-level job (Category $0 / 1$ in the DOT). This assignment requires the student to take a more directive role in the session. Conducting a Job Analysis requires that they conduct a structured interview of an individual and often that person's supervisor, co-workers, and Human Resources Manager to obtain specific information. They are not allowed to use their own worksite or those of friends or relatives. This emulates activities that they may encounter in working with individuals who incurred an injury affecting their ability to return to work. The general occupational and labor market information learned in the class must be distilled and applied to a particular job and work setting. In addition, the students are exposed to the process of evaluating the essential tasks and duties of a particular job, addressing possible job or job site modifications, and assessing reasonable accommodations.

Two classes required in the MRC program focus on the development of specific counseling skills - Techniques for Counseling Interviews and Theories and Techniques of Group Counseling. Each of these classes incorporates a three-day intensive workshop in which the students practice and demonstrate mastery of the skills taught during the class. Each student has the opportunity to function as the counselor in multiple one-on-one or small group sessions with observation by a faculty member who is an experienced counselor. These sessions do not use "canned" scenarios. Instead, the student acting as the client presents a real issue to be dealt with in the session. Each session is a "live" counseling session, and the student functioning as the counselor receives feedback from both the client and the faculty member.

During the Rehabilitation Case Management class, the form of experiential learning shifts to a Service Learning Task. In the MRC program, the class has been positioned somewhat as a capstone class. It is typically taken in the term prior or along with the Practicum experience. The experiential learning in the previous classes provides a foundation for the students' involvement in the actual service delivery process. For the purposes of this RCM class, Service Learning is defined as a process through which students are involved in community work that contributes significantly to: 1) positive change in individuals, organizations, neighborhoods and/or larger systems in a community; and 2) students' academic understanding, civic development, personal or career growth, and/or understanding of larger social issues.
In the RCM class, the major class assignment is the development of a "typical" rehabilitation case from the initial intake report through the evaluation, planning, service delivery, and closure process. Each student develops a fictitious client and selects a particular illness, injury, or condition which produces a need for rehabilitation services. As part of this assignment, the student is to identify specific client needs and develop a service delivery plan to address those needs. In the class, the student is exposed to a variety of rehabilitation settings as well as typical services necessitated by a number of specific disabling conditions. Meaningful case management typically involves both the delivery of direct services and securing services from a wide variety of other resources. Often, identifying appropriate community resources and securing entry into the process will be the most challenging part of implementing a rehabilitation plan. Sound case management does not allow for essential needs to go unmet just because the services are not easily obtained. In the Service Learning activity, the student is realistically exposed to the process of assessing needs, developing resources, and actually delivering the services.

The task selected by each student can be related to the needs of the fictitious client or can be based on real needs existing within the student's local communities for individuals with disabilities. Based on this analysis, the second step of the process is to identify existing resources with the capacity to provide the service. If an existing resource is identified, the student is to establish contact with the resource to see if participation in the service delivery process or possibly enhancement of the services being delivered is possible. If no provider is located, the task shifts to seeking an "Umbrella" organization that might be interested in the student developing a program or service within the organizational structure. The student works with this organization to develop the appropriate service. The services can certainly transcend a particular client and may be beneficial to others in the community with similar needs.

The third step in the process is to analyze the use and benefit of the service. If it proves beneficial, this should also include a plan for facilitating sustainability of the service. The final step is completion of two reflection papers. The first reflection paper covers the initial need analysis and identification of the service provider or umbrella organization. This is due at the midpoint of the academic term. The second reflection paper covers the student's participation in the service delivery process, outcomes sustainability, and the student's growth as a result of the experience. This is completed at the end of the academic term. Figure 2 illustrates the specific format to be followed for each of the reflection papers. 
Vol.2. No.1 Feb, 2014, pp. 11-17

\begin{tabular}{|c|c|}
\hline INTRODUCTION & What is the task and what aspects of the exercise is the student working on? \\
\hline WHAT & $\begin{array}{l}\text { What actually occurred during the reflection period including the steps taken, individuals } \\
\text { contacted, problems encountered, and outcomes? }\end{array}$ \\
\hline SO WHAT & $\begin{array}{l}\text { Reflect on how these steps contributed positively or negatively to the project (how were they } \\
\text { important). }\end{array}$ \\
\hline NOW WHAT & $\begin{array}{l}\text { What comes next? Is the service now available or enhanced? How will it be sustained? Who will } \\
\text { assume responsibility for it? }\end{array}$ \\
\hline IT DID YOU LEARN & $\begin{array}{l}\text { Discuss your feelings about the experience as well as your perception about what went well and } \\
\text { what did not go well. }\end{array}$ \\
\hline
\end{tabular}

Figure 2. Reflection Paper Flow Chart

Given the geographic distribution of the students, the types of projects have been indeed varied. Some of the students established "Dress for Success" clothing closets at local churches or community centers for financially distressed individuals needing suitable clothing for interviews or employment. In some cases, they found existing services only had clothing for women and expanded the service to include clothing for men. In other cases, state agencies could only offer employability skills training a few times each week or month or only in centralized locations. With the additional help of the students, the scope and availability of services could be expanded with no additional cost to the agencies. Other students initiated support groups for individuals with specific types of disabilities. In many cases, the activities were sustained by the students after the conclusion of the term because they found the activities and contribution to their communities satisfying. So far, there have not been any students reporting that the assignment was not beneficial. There were many who expressed a material improvement of their understanding of the problems and constraints experienced by individuals with disabilities as well as by those attempting to serve them. Additionally, most felt more confident in their ability to make effective use of community resources.

The final stage of the program involves the field placements - Practicum and Internship. The Practicum is 100 hours and is focused on further development of students counseling skills under the supervision of experienced site and faculty supervisors. In the Internship, students complete 600 hours in which they function as Rehabilitation and/or Mental Health Counselors. Again this is done under the supervision of experienced site and faculty supervisors. In each case, the student is assigned "real" work with responsibility for documentation and outcomes. Although the emphasis in this type of experiential learning leans back towards primarily benefiting the student and focusing on the student's learning, there are obviously benefits to the organization and the recipient of the services as well. In this activity, as in the previous ones, a key element of the experience is the completion of the reflection paper. Frequent comment threads in these final reports were that actually working in the counseling and service delivery environment for extended periods really helped to put the academic preparation into the proper perspective, and that students felt more confident in their ability to function as a professional.

\section{Challenges in an Online Environment}

Some of the challenges in providing experiential learning as part of an online program were discussed by Strait and Sauer (2004). In their article "Constructing Experiential Learning for Online Courses: the Birth of E-Service", they see the global challenge as being able to provide a quality experience in service learning while meeting the needs of multiple students in multiple communities. They report that while the individual projects may be smaller and have less overall impact on the organization, they may prove more beneficial in their ability to tailor the projects to the student's own major interest. In addition, multiple community partners can benefit from the varied projects.

In her article, "A Guide to Incorporating Service Learning into Counselor Education", Dockery (2011) makes the case for pre-practicum service learning as part of graduate-level counselor training. One of the elements she saw contributing to success was making contact with potential community partners well in advance and developing an ongoing relationship in which students can be assigned to the organization on a recurring basis. While there is certainly merit in this for programs that are more campus-based, the dispersion of student in an online program diminishes the likelihood of regular use of the same organizations or facilities on a regular basis. It also limits the possibility of site visits.

In developing the MRC program's experiential learning components, attempts were made to emulate or actually experience the conditions under which many rehabilitation counselors work. Quite often this is in a small decentralized office with clients living away from the counselor's office. As mentioned earlier, service delivery is often dependent on local community resources. Therefore, the program felt that incorporating the identification and development of the local providers was an essential part of the experiential learning process for the individual student. Thus insistence that the student be actively engaged in this, rather than the faculty providing preselected sites, was incorporated into the assignments.

Stone (2006) found that student satisfaction with online classes was, at least in part, determined by their ability to build a relationship with the instructor as well as with others in the class. Therefore, instructors should consider methods such as collaborative assignments, site visits, and encouraging good communication between the instructor and the students as well as among the students. Degiogio's 
(2009) study of Rehabilitation Counselor distance education found that students liked the flexibility and convenience, felt that the quality was learning was equal to or better than traditional classes, and improved their comfort with technology.

There were some negative themes as well. Three prominent areas were: problems with technology, feeling disconnected, and too much material in the course. Based on her study, she concluded that student outcomes were affected by the frequency and structure of interaction with faculty and other students, and that immediate, personal, and individualized feedback regarding their clinical skills produced the most positive outcomes. Similar positive and negative findings were found in the supervision of Master's Level Rehabilitation Counseling students (Morrissette, Bezyak,\&Ososkie, 2012).

The MRC program's efforts to address these issues are reflected in the structure of most of the classes. Many of the classes involve discussion forums and projects to promote a sense of collaboration. There is extensive use of video streams to provide a personality for the class rather than simply having drop boxes for collecting and grading assignments. The two classes requiring counseling skills workshops (totaling six days) are usually taken during the third or fourth term and provide an opportunity for the for the students to personally interact with the faculty and other students. This again promotes cohesiveness and familiarity. During the fieldwork experience, each student is assigned to a small class section with frequent phone or videoconferencing contacts with the faculty supervisor. In addition, each has a site supervisor who provides immediate feedback on performance. Also, each of the experiential learning tasks as well as the Practicum and Internship require the student to submit reflection papers describing the individual's growth process.

A good organizational infrastructure is essential A couple of other elements that are considered key to the success of an online approach are the availability of good technical support, for both students and faculty, and an on-going interaction with an individual faculty advisor. Locally, the MRC program has a Blackboard Student Support staff which is specifically dedicated to addressing student problems and issues related to online classes. There is a separate faculty support group which assists faculty with course design and functionality as well as problem resolution. As a result, most technology issues can be resolved quickly with little interference with the learning process. Each active student is assigned a faculty advisor who can be readily reached via phone or email. This provides continuity and a sense of belonging throughout the student's participation in the program.In addition, student and graduate email lists are maintained to provide general information, reminders and encouragement.

\section{Conclusion}

This experiential learning model has applications to many different types of human services education programs that are delivered primarily online. The concepts could be adapted for online graduate or undergraduate education programs in Mental Health Counseling, Social Work , Speech Pathology, and Health Care Administration to name a few. Any educational program that has a community services or public interaction component could possibly benefit from incorporating this model into the students' online experience.

\section{REFERENCES}

35th Institute on Rehabilitation Issues.(2010). eLearning and Vocational Rehabilitation. Hot Springs, AR:University of Arkansas CURRENTS.

Chan, F., Leahy, M., Lui, J., \&Shaw, L. (1997).Preparation of rehabilitation counselors for case management practice in health care settings.Journal of Rehabilitation,63, 53-59.

Chan, F.,Chronister, J., Allen, C., Catalano, D., \& Lee, E. (2004).Foundations of rehabilitation counseling.Retrieved from:http://counseling.sfsu.edu/pdfs/FoundationsRehabilitationCo unseling.pdf.

Council on Accreditation of Counseling and Related Education Programs. (2009). CACREP 2009 Accreditation Standards, Section 1.H. Retrieved from: http://www.cacrep.org/doc/2009Standardswithcover.pdf.

Council on Rehabilitation Education.(2010). CORE Accreditation Manual for Masters Level Rehabilitation Counselor Education Programs, Section 2. C. D.Retrieved from: http://www.core-rehab.org/Files/Doc/PDF/COREStandardsProgra ms.pdf.

Degiogio, L. (2009). Examining Distance Education in Teaching Clinical Counseling Skills to Rehabilitation Counselors-in-Training.(Unpublished doctoral dissertation). Tucson, AZ: University of Arizona.

Dockery, D. J. (2011).A Guide to incorporating service learning into counselor education.Retrieved from: http://counselingoutfitters.com/vistas/vistas11/article_34.pdf.

Experiential Learning.(n.d.). Retrieved January 15, 2013 from the OLPCWiki:http://adulteducation.wikibook.us/index.php? title=Experiential_Learning

Field Experience.(2011). University of Texas at Dallas, Teacher Development Center.Retrieved from:http://www.utdallas. edu/teach/field_experience/early_field_experience.html.

Furco, A. (1996). Service learning: A balanced approach to experiential education.Washington, DC:Corporation for National and Community Service.

Jett, S. T., \&Delgado-Romero, E. A. (2009).Prepracticum service-learning in counselor education: a qualitative case study.Retrieved from: http://www.highbeam.com/doc/1G1-130832 71.html/print.

Maki, D.R., \&Tarvydas, V. (Eds.).(2011). Rehabilitation 
Vol.2. No.1 Feb, 2014, pp. 11-17

counseling theory and practice. New York: Springer.

Morissett, S., Bezyak, J. L., \&Ososkie, J. N. (2012).A closer look at distance-based supervisory relationships in master's level rehabilitation counseling programs.Journal of Applied Rehabilitation Counseling, 43, 3-7.

Murray, C. E., Pope, A. L., \& Rowell, P. C. (2010).Promoting counseling students' advocacy competencies through service-learning.Journal for Social Action in Counseling and Psychology. 2,29-47.

Rubin, S.E., \& Roessler, R.T. (2008).Foundations of the vocational rehabilitation process (6th ed.). Austin, TX: Pro-Ed.

Stone, V. (2006).Student satisfaction with and perceptions of relationship development in counselor education videoconferencing courses.(Unpublished doctoral dissertation). Blacksburg, VA: Virginia Polytechnic Institute and State University.

Strait, J., \& Sauer, T. (2004).Constructing experiential learning for online courses: The birth of E-service.Retrieved from: http:/www.educause.edu/ero/article/constructing-experienti al-learning-online-courses-birth-e-service. 